\section{On listening}

I have nothing to live for." Helen spoke softly. A bright and articulate woman at 86 , this was the first time in 20 years that I had heard these words from her. She suffered from chronic osteoarthritic pain in her joints, and fatigue and dizziness related to difficult-to-control congestive heart failure. Her nonsteroidal antiinflammatory drugs had been withdrawn because of heart failure and her cardiac medications resulted in symptomatic hypotension. Her medication regimen involved a delicate trade-off between effective treatment and adverse effects.

"I can no longer travel. I can hardly walk. My kids are grown and have moved away. They don't need me any more. I sometimes wonder why we are trying so hard to keep me around. My life has no purpose, no meaning."

Helen looked away tearfully. Silence. My resident Lisa appeared uncomfortable.

"Yes you do! You have purpose," Lisa chirped. "Tell Dr. Lee what's happening this afternoon! Who's coming this afternoon?"

Helen smiled. "My newest grandchild from Denmark. My son will be visiting this afternoon." She paused. "I do look forward to holding him. But ... they don't need me. All my life I've cared for others. I can't do that anymore."

Lisa's words reminded me of some of my own, perhaps 20 years ago. I can well remember the discomfort of wanting to fix problems for which there were no fixable solutions, of wanting to provide comfort to the suffering patient but not knowing the "right" words to use. Those awkward periods of silence. The biomedical model of my medical training in the 1980s provided little help with this.

I have learned over time that sometimes, we simply need to listen.

Charon writes, "A scientifically competent medicine alone cannot help a patient grapple with the loss of health or find meaning in suffering. Along with scientific ability, physicians need

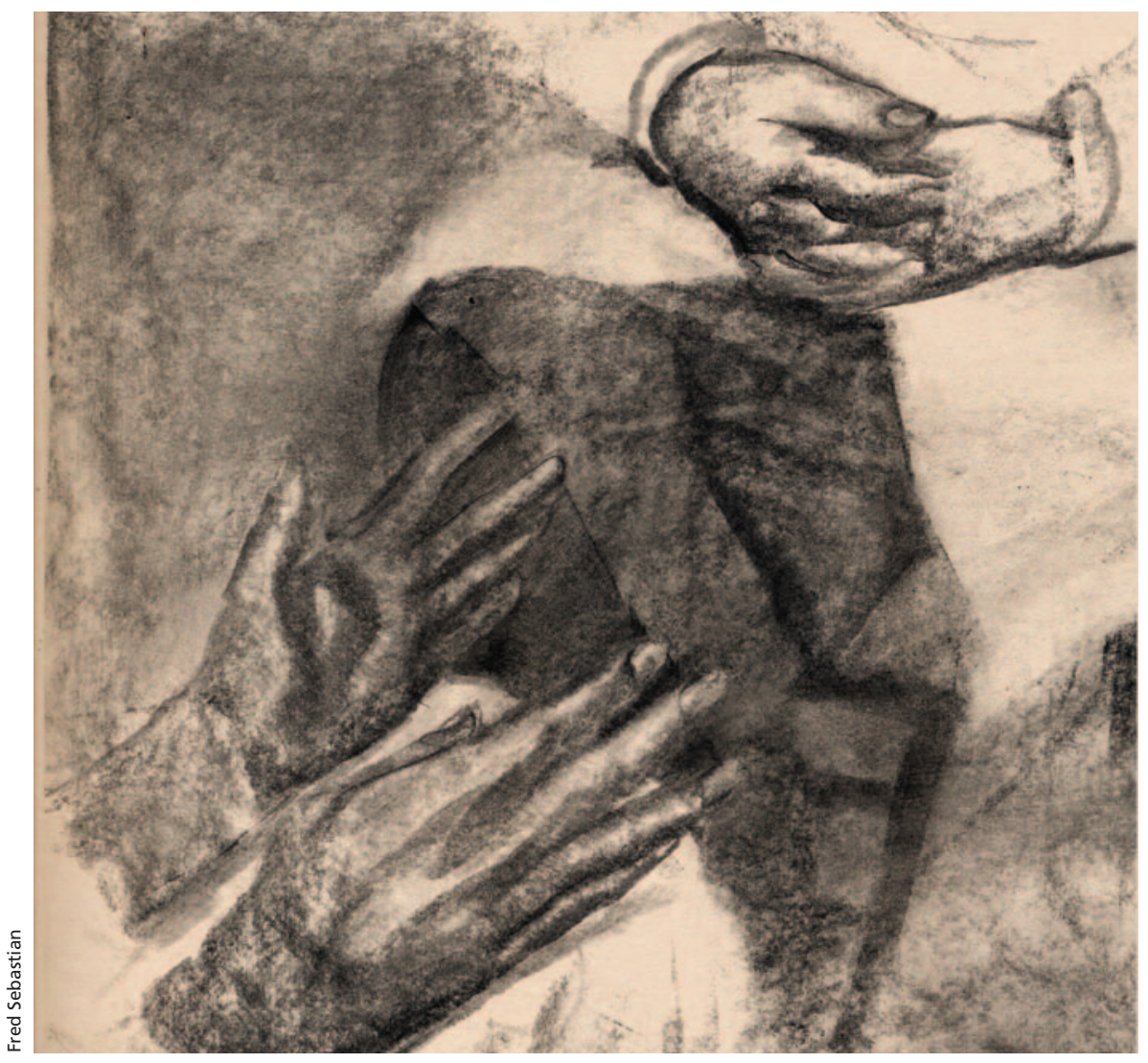

the ability to listen to the narratives of the patient, grasp and honor their meanings, and be moved to act on the patient's behalf."

Honouring the patient's meaning requires that we refrain from imposing our own meaning and values on to their story. Mezirow describes the frames of reference adults acquire through experience, which define their life world. ${ }^{2}$ These frames of reference shape expectations, perceptions, cognition and feelings, and create a specific point of view that will differ for each of us. Meaning must therefore be the patient's own and determined in the context of the patient's life.

Nichols writes of the importance of listening. "By momentarily stepping out of his or her own frame of reference and into ours, the person who listens well acknowledges and affirms us. That affirmation, that validation is absolutely essential for sustaining the self-affirmation known as self-respect. Without being listened to, we are shut up in the solitude of our own hearts." ${ }^{\prime 3}$

Nichols emphasizes the importance of making listening an active process that involves a deliberate effort to suspend our own needs and reactions - in essence, a suspension of self - and to immerse in the other. To listen well, we must hold back what we have to say and control the urge to interrupt or argue. "You need to be silent. You need to be selfless."

Nichols writes, "A lot of failed listening takes the form of telling other people not to feel the way they do." The effect is to not acknowledge their feelings. "Reassuring the person that there's nothing to worry about is not responsive to him; it's responsive to the listener's own uneasiness." ${ }^{3}$

So, how does good listening help with healing? When patients are allowed to tell their story, they are no longer isolated in their suffering. The telling of their story may also help them to achieve a critical distance from 
their pain. Frank writes, "people tell the stories they need to tell in order to work through the situation they are in.... When experience becomes an object for what is now a mutual involvement, the teller gains some distance between what is being lived and what is being told. Only at this distance can actions — including interpretations — be perceived as possibly having alternatives, thus making change imaginable."

So I pulled up a chair beside Helen. I sat and I listened. Being half her age, I did not have her life experience or knowledge of her perspectives as the basis for making assumptions about how she might feel or ought to feel. It was important to accept her story and in doing so, honour and validate her suffering. I encouraged her to share her thoughts on meaning and purpose, spirituality, supports and hope.

Over time, I have become aware that a humanistic orientation benefits not only the patient, but the physician as well. In truly listening, in suspending our own perspectives and agenda, we are offered the privilege of learning how others deal with, and make sense of, suffering. Frank believes that "humans do have to suffer; call it our existential destiny. But there are better ways to suffer; call those ways grace." 4

In medicine, we often bear uncomfortable witness to the reality of what experience has in store for many of us. In listening to our patients, we learn invaluable lessons from those making their journey ahead of us.

\section{Linda L.W. Lee MD}

Assistant clinical professor

Department of Family Medicine

McMaster University

Hamilton, Ont.

\section{REFERENCES}

1. Charon R. Narrative medicine: a model for empathy, reflection, profession, and trust. JAMA 2001;286:1897-902.

2. Mezirow J. Transformative learning: theory to practice. New Directions for Adult and Continuing Education 1997;74:5-12.

3. Nichols MP. The lost art of listening. New York (NY): The Guildford Press; 1995. p. 15.

4. Frank AW. Just listening: narrative and deep illness. Fam Syst Health 1998;16:197-212.

\section{Poem}

\section{Imperfect knowledge}

My toes wriggled, skeletal within new shoes big toe, little ones as $\mathrm{x}$-rays passed through me, no worry of roentgens or rads. I stepped off the pedestal, laughed, and the shoe salesman smiled, said "Look again, if you like," and we both watched the goodness of the fit.

My father, a general-all-around doc, made use of $x$-rays too.

How many chest films did he perform, set fractures under fluoroscopy, not realizing danger of overexposure, no lead to shield his body.

In the end, did it matter? Heart disease caught up with him, his hundred-patient days,

not cancer.

After the first coronary, his face a fractured moon, grey within the mist of a plastic oxygen tent, I thought he would break apart, never return to us.

Before the lethal second blow, I saw him in the kitchen, taking red pills from the fridge.

"Estrogen," he said.

"They tell me it's good for my heart.

"I'd grow breasts, if I had to."

Yes, yes, I hoped then but now know it wasn't so.

\section{Richard Bronson MD}

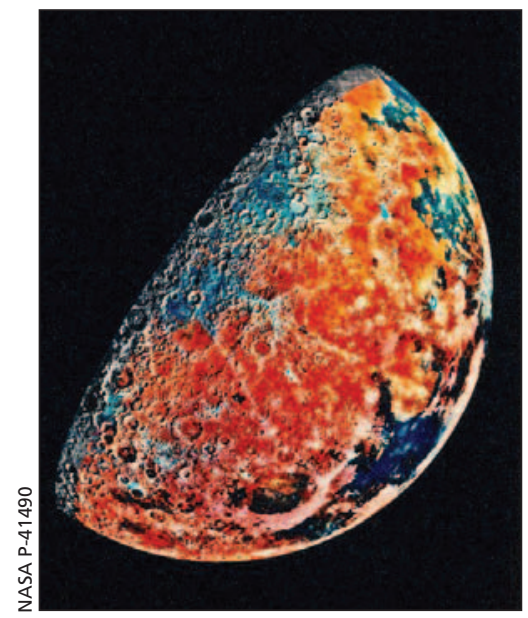

Professor, obstetics, gynecology and pathology

Stony Brook University Stony Brook, NY

Dr. Bronson's father, a general practitioner, was the inspiration for this poem; others are gathered in Search for Oz (Padishah Press). 